\title{
O buraco negro do pemedebismo
}

M DOS GRANDES méritos do livro Imobilismo em movimento de Marcos Nobre, filósofo e professor da Unicamp, é a criação da categoria pemedebismo. Por meio dela, o autor reconstitui a lógica conservadora do sistema político brasileiro na transição democrática, de 1979 até hoje, que teria resultado em uma blindagem das instituições à participação popular. O tema vem a calhar: com as revoltas de junho de 2013, as contradições entre sistema político e forças sociais simplesmente adquiriram carne e osso. Os protestos deram vasão a um sentimento antipemedebista, que eclodiu de modo relativamente espontâneo e desorganizado. Mas em que consiste, afinal, o pemedebismo?

\section{Origens do pemedebismo}

Segundo Marcos Nobre, o pemedebismo é o modus operandi de uma cultura política essencialmente conservadora, de baixo teor democrático, formada e estabelecida nas instituições brasileiras desde os anos 1980. Não se refere apenas ao PMDB, ainda que a legenda tenha sido protagonista de seu surgimento.

A história começa em 1979, quando a abertura ao pluripartidarismo engendrou o temor, entre líderes do então MDB, da perda do monopólio da oposição. Para evitar a fragmentação e a consequente pulverização de seu papel histórico, o PMDB estabeleceu um princípio norteador e uma forma organizativa que, posteriormente, encarnaram nos três poderes da República. O princípio norteador era o bloqueio da participação popular direta e a garantia do controle conservador da transição. José Sarney é a figura mais representativa desse propósito: um quadro do PFL, derivado da Arena, aliado e depois filiado ao PMDB. Para garantir a blindagem do sistema político, seria necessário atrair para dentro do partido a maior quantidade possível de agrupamentos que resguardassem a ordem. Foi criada, então, a forma organizativa do pemedebismo: um sistema de vetos, pelo qual cada fração que fosse suficientemente forte para chantagear as outras exerceria seu poder de obstrução das iniciativas indesejáveis. $\mathrm{O}$ sistema de vetos se externalizou com a bancada conhecida como Centrão na Constituinte de 1988, que ocupou o espaço de mediador inescapável de quase todos os partidos que disputavam os rumos da redemocratização. $\mathrm{O}$ preço de não negociar com o Centrão era um considerável isolamento.

O autor recorda que uma das conquistas do Centrão foi atrelar as demandas sociais incorporadas no texto constitucional às leis complementares que dependiam de regulamentação posterior. Dessa forma, garantias sociais foram aprovadas, porém postergadas. Só seriam efetivas caso o pemedebismo as tolerasse. O resultado, já conhecemos: uma Constituição largamente mais social-democrática do que a realidade brasileira.

\section{Condomínio pemedebista}

Quando essa lógica se consolidou, após o impeachment de Collor, o sistema político brasileiro já estaria então constituído como um "condomínio pemede- 
bista". Novos loteamentos puderam surgir na particular correlação de forças dos partidos políticos dominantes, desde que houvessem incorporado o princípio da blindagem conservadora. Com a noção de "condomínio pemedebista", o filósofo demarca o autoritarismo inerente da democracia brasileira, rejeitando a ideia de "presidencialismo de coalizão" que, segundo ele, aparenta descrever um sistema muito mais democrático do que aquele realmente existente (2013, p.15-16).

A particularidade do pemedebismo em relação a outras "democracias blindadas" do mundo contemporâneo se concentraria em cinco procedimentos típicos. Em primeiro lugar, o governismo: estar sempre no governo, independentemente de qual força política o dirige. Foi assim que o pemedebismo gestou partidos políticos anódinos e amorfos, cuja única finalidade é ampliar seu próprio lote no condomínio, independentemente de quem seja o síndico. Em segundo lugar, a criação de supermaiorias legislativas como instrumento estratégico de ameaça e, afinal, como arma principal do sistema de vetos. Em terceiro lugar, uma hierarquia desses vetos, isto é, as fronteiras móveis pelas quais seria possível contorná-los. Em quarto lugar, a obstrução da entrada de novos membros no condomínio, que encontrou recente expressão na proposta da cláusula de barreira. E em quinto lugar, a prática de evitar, sempre que possível, qualquer debate público, realizando negociações preferencialmente nos bastidores e impedindo que discussões ultrapassem os corredores dos gabinetes. Esses cinco procedimentos foram incorporados ao sistema político com tal profundidade, que exercem a atração de um buraco negro sobre todos os partidos que se aproximam.
O mote da governabilidade, combinado a um refluxo geral das lutas sociais de massas depois de 1992, consolidou o pemedebismo como lógica essencial do sistema político. A partir de então, aqueles que pretendessem dirigir o país teriam, antes, que dirigir o pemedebismo.

Segundo Nobre, foi esse o mesmo caminho que permitiu que Fernando Henrique Cardoso implementasse o bem-sucedido Plano Real em 1994 e que Lula pudesse lançar mão de seus programas de transferência de renda a partir de 2005 (marcadamente o Bolsa Família, o aumento do salário mínimo e o crédito consignado). O PT, que nos anos 1990 demarcou o espaço de força antipemedebista, teria também sucumbido à atração do buraco negro após o escândalo do mensalão. A tática petista teria sido, então, a "ocupação pela esquerda do pemedebismo" (2013, p.103) - se é que isso é possível.

Associar-se ao condomínio exige pagamento de altos dividendos. Como destacou o autor, o pemedebismo nunca perdoa uma dívida. Sendo assim, após atrair o PT, seu mais forte polo opositor dos anos 1990, o pemedebismo deu origem a dois movimentos. Primeiro, a eliminação da oposição e consequente fim da polarização programática real na democracia brasileira. Segundo, a consolidação da blindagem do sistema político. Assim, garantiu sua essência conservadora com considerável estabilidade até junho de 2013, quando todos os procedimentos típicos da cultura política autoritária que estruturou a redemocratização do Brasil foram irremediavelmente alvejados.

\section{Ciclos históricos}

O autor também tem o mérito de propor uma periodização interessante da 
transição democrática, na qual identifica três ciclos históricos. O primeiro, entre 1979 e 1994, foi marcado pela criação e consolidação do pemedebismo. Apesar de a inflação figurar como principal problema a ser resolvido pelo governo brasileiro de então, o pemedebismo não foi capaz de solucioná-lo, pois não estava disposto a romper bruscamente com o paradigma de regulação dos mercados herdado da ditadura, uma vez que seria próprio da sua natureza imobilista procrastinar qualquer ordem de mudanças significativas. Foi Collor quem teria aberto o caminho do desmonte desse paradigma.

No segundo período, entre 1994 e 2002, FHC logrou dirigir o pemedebismo para executar as adiadas mudanças econômicas. Os tucanos responderam ao problema da inflação com o Plano Real, com a forte centralização da política fiscal sob a égide do governo federal e com a adoção de um pacote neoliberal (juros altos, privatizações de setores estratégicos, abertura econômica, superávit primário, política salarial restritiva). Se o período anterior foi marcado por uma luta do PMDB para comandar seu condomínio, já aqui o centro da disputa se deslocou para a polarização entre PT e PSDB. Nos anos 1990, enquanto o PT estava disposto a garantir as conquistas sociais da Constituição, o PSDB se mostrou propenso a rifá-las em nome do combate à inflação. A vitória dos tucanos se explicaria porque, ao mesmo tempo que conseguiram dirigir o pemedebismo, priorizaram a solução do problema mais emergencial do país. Ao solucioná-lo, contudo, não souberam dar o próximo passo.

O terceiro período, iniciado com a vitória eleitoral de Lula em 2002, mar-
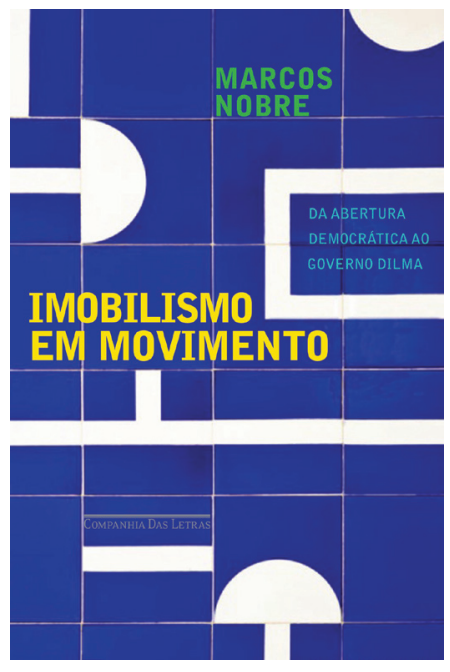

Nobre, M. Imobilismo em movimento. São Paulo: Companhia das Letras, 2013.

cou a substituição do problema nacional norteador da polarização. Com a inflação controlada, emergiu no centro das disputas a questão das desigualdades sociais, principal objeto do debate público. Contudo, se por um lado o PT buscou se diferenciar de seu antecessor com políticas mais amplas de compensação social, não abandonou os cânones da ortodoxia neoliberal e tampouco conseguiu se livrar do pemedebismo, imiscuindo-se em sua lógica. Obcecada com o problema já contornado da hiperinflação e adivinhando uma heresia econômica do petismo que simplesmente não ocorreu, a oposição tucana perdeu fôlego, dando origem ao que Nobre chama de "fim da polarização". Ou, em outras palavras, a vitória retumbante do pemedebismo.

\section{Canoa furada?}

Apesar dessas virtudes, o livro de Marcos Nobre apresenta um déficit conceitual que compromete relativamente sua proposta: uma forte imprecisão a res- 
peito dos conceitos de desenvolvimento e desenvolvimentismo. ${ }^{1} \mathrm{O}$ autor organiza sua narrativa a partir das noções de "cultura política" e "modelo de sociedade", que expressariam "processos sociais mais profundos" do que as convencionais esferas da política e da economia (2013, p.22). A trajetória do pemedebismo faz parte da dimensão da cultura política e constitui o fio condutor forte do ensaio. Porém, no que diz respeito à dimensão nomeada como "modelo de sociedade", a análise fica aquém do esperado. Sendo essa uma espécie de fio condutor auxiliar, alguns problemas se disseminam ao longo do livro.

Para Nobre, um "modelo de sociedade não é apenas um programa econômico, nem somente uma maneira determinada de entender a política, mas um padrão de regulação social mais amplo" (2013, p.22). Em seu esquema, as noções de "nacional-desenvolvimentismo" e "social-desenvolvimentismo" seriam modelos de sociedade específicos, adotados durante ciclos históricos determinados. O problema é que sua análise econômica traz indefinição e incoerência sobre o significado de desenvolvimento. Com isso, sua interpretação corre o risco de se converter em uma espécie de canoa furada. Limito-me a elencar uma fonte e duas propagações desse problema.

\section{Nacional-desenvolvimentismo antes de 1980}

Em primeiro lugar, a fonte da imprecisão está no uso genérico do termo "nacional-desenvolvimentismo". Ao de-finir o modelo de sociedade do período anterior à crise da hiperinflação dos anos 1980 a partir do amplo guarda-chuva conceitual de um indeterminado "nacional-desenvolvimentismo", o autor comete o deslize de abarcar, em uma mesma categoria, o projeto de João Goulart e o dos militares. Mas o debate histórico sobre o desenvolvimento nacional dos anos 1930 aos 1970 confrontou intelectuais e lideranças brasileiras com visões de mundo radicalmente opostas. Ao desconsiderar as profundas clivagens internas presentes no paradigma desenvolvimentista, empacotando-as em um mesmo "modelo de sociedade", Nobre cria uma teleologia na qual o golpe militar de 1964 perde o sentido. Em outras palavras, dentro do paradigma desenvolvimentista, se chocaram tendências ideológicas de extrema esquerda (socialistas) e extrema direita (fascistas), passando por reformistas de tipo socialdemocrata, trabalhista ou elitista. Assim, tanto o debate ideológico quanto o debate distributivista no interior desse paradigma foram e são centrais para qualquer consideração histórica do tema. Como decorrência, Nobre criou uma tábula rasa do período anterior a 1980.

É por isso que seu ensaio sucumbe à tese do "milagre econômico", repetindo a ideia de que durante a ditadura militar teria ocorrido uma "melhora geral" dos padrões de vida brasileiros sobre a qual se apoiou a "desigualdade sustentável" do modelo de sociedade adotado (2013, p.29-31). Desconsidera-se, assim, o largamente investigado arrocho salarial do período, componente estratégico do projeto militar, que se localizava no polo conservador do paradigma desenvolvimentista (por exemplo, ver Costa, 1997). Muito diferente, portanto, do projeto de capitalismo social-democrático de João Goulart e Leonel Brizola, para não mencionar a revolução brasileira de Caio Prado Jr. Ao desconsiderar os debates ideológicos e distributivistas no interior do modelo de socieda- 
de nacional-desenvolvimentista, Nobre desresponsabiliza-se de identificar os pressupostos conflitantes que sustentam esse termo, o que explica seu emprego errático.

\section{Nacional-desenvolvimentismo e pemedebismo}

A tábula rasa do "nacional-desenvolvimentismo" dá origem a um problema mais grave quando essa noção indeterminada se projeta para o período privilegiado do ensaio: a transição democrática. A formação do pemedebismo coincidiria com a crise do modelo de sociedade nacional-desenvolvimentista, em plena turbulência depois de dois choques do petróleo e do "choque Volcker" (2013, p.32). Nobre sustenta que "como representante de setores nacional-desenvolvimentistas tradicionais, o pemedebismo se viu confrontado com a inevitabilidade do desmonte do modelo e teve de se adaptar à nova situação. A partir daí, o pemedebismo estava limitado ao balcão das compensações caso a caso, aos acertos de bastidores" (2013, p.88, grifos nossos). Três questionamentos direcionados a essa afirmação parecem pertinentes para uma percepção crítica do nexo entre nacional-desenvolvimentismo e pemedebismo.

Em primeiro lugar, quem seriam, afinal, os "setores nacional-desenvolvimentistas tradicionais"? Nobre não deixa claro, uma vez que não estabeleceu os parâmetros de diferenciação interna do nacional-desenvolvimentismo. Ainda que seja fácil supor que se trata dos setores conservadores, permanecemos sem saber com quais pressupostos o autor trabalha para defini-los.

Em segundo lugar, se o pemedebismo era representante desses setores, isso o enquadraria em um determinado lugar programático, ainda que flexível. Entretanto, ao elencar os procedimentos típicos dessa cultura política, Nobre enfatiza justamente seu caráter pouco programático e amórfico. Disso surge o seguinte impasse: ou o pemedebismo era representante desse nacional-desenvolvimentismo tradicional, ou era suficientemente versátil para se adaptar ao mais feroz neoliberalismo, sem nunca sair do centro da vida política brasileira. De acordo com elementos do próprio ensaio, a segunda hipótese guarda mais semelhança com a realidade.

O que nos leva ao terceiro ponto: seria esse desmonte do modelo de sociedade um "limitador" do pemedebismo? De acordo com o próprio autor, a crise do modelo de sociedade coincidiu precisamente com a gestação da cultura política pemedebista. Foi a lógica do pemedebismo que passou a ditar os ritmos e sentidos das mudanças que se seguiram, tirando proveito do desmonte nacional-desenvolvimentista e dele se desembaraçando com relativa agilidade rumo às privatizações. $\mathrm{O}$ neoliberalismo e seu vórtice fragmentário, enfim, parecem ter catalisado o pemedebismo e não the imposto qualquer tipo de limite.

Em suma, não parece haver uma identificação suficientemente nítida entre a cultura política pemedebista e o modelo de sociedade nacional-desenvolvimentista, como pretende Nobre, o que se soma à indefinição do significado de desenvolvimento.

\section{Social-desenvolvimentismo}

Outro problema, derivado da mesma indeterminação, está no uso do rótulo "social-desenvolvimentismo" para o projeto impulsionado pelos governos 
do PT. Não são indicados, novamente, quais parâmetros sustentam o emprego do termo. Sobre isso, o autor entra em contradição.

Por um lado, Nobre afirma a continuidade da ortodoxia "tipicamente neoliberal" de FHC, destacando inclusive que "o governo Lula manteve e até mesmo aprofundou a política econômica implantada em 1999" (2013, p.106). Essa política consistiria em um pacote composto por aumento de taxas de juros, câmbio flutuante, abertura desregulada ao capital estrangeiro, metas de inflação, superávit primário, desvinculação de receitas da União, privatizações/concessões de setores estratégicos e infraestrutura, Lei de Responsabilidade Fiscal, Reforma da Previdência, entre outros. Some-se a isso o período em que o câmbio esteve artificialmente elevado, como consequência irrefletida da política monetária estadunidense após a eclosão da crise de 2008, o que logicamente dificultou a atividade da indústria nacional. Em síntese, postula-se que "o governo Lula prosseguiu o trabalho do anterior de desmonte do amálgama de pemedebismo e nacional-desenvolvimentismo" (2013, p.117-8, grifos nossos).

Por outro lado, Nobre escreve que a tática petista a partir de 2005 "significou nada menos do que a consolidação da primeira imagem do social-desenvolvimentismo, um modelo de sociedade internamente vinculado à democracia e marcado pelo combate às diferentes formas de desigualdade" (2013, p.103, grifos nossos). Mas, afinal, os governos petistas foram desenvolvimentistas ou prosseguiram o trabalho de desmonte desse modelo de sociedade?

Ainda caracterizando os governos petistas, Nobre alega o surgimento de um "novo padrão de desenvolvimento", que teria realizado "uma rápida adaptação do país ao boom de commodities e a uma economia global movida pela gangorra EUA-China" (2013, p.118). Ora, não há nada mais velho no Brasil do que a exportação de matérias-primas. Em outras palavras, a despeito da ampliação das políticas compensatórias, a ortodoxia neoliberal constituiu um pacote de desestímulo ao investimento produtivo dos setores voltados para o mercado interno e um hiperestímulo ao segmento primário-exportador, que carregou o crescimento econômico da década de 2000. Definitivamente, não se trata de um "novo padrão". Para discuti-lo, há uma pergunta estratégica: quais setores sociais brasileiros foram imediatamente favorecidos pelo boom de commodities e pelos juros altos?

Poder-se-ia, enfim, alegar que os governos petistas adotaram uma "política anticíclica" de incentivo ao consumo após a eclosão da crise, o que amorteceu seus impactos durante um período determinado. Entretanto, seria o incentivo ao consumo item suficiente para o emprego do termo desenvolvimentismo, quando quase todos os outros sinais apontam para outro lado?

De fato, houve uma pequena inflexão no governo Dilma entre maio de 2011 e agosto de 2012, que o cientista político André Singer definiu como "ensaio desenvolvimentista". Além de baixar os juros e experimentar algumas medidas macroprudenciais, o governo desonerou o investimento privado e liberou financiamentos do BNDES. Contudo, as expectativas foram rapidamente frustradas. Não podemos nos surpreender com o fato de que uma burguesia convertida ao rentismo e habituada a 
juros estratosféricos há mais de vinte anos não tenha respondido com investimentos produtivos quando esses foram momentaneamente facilitados pelo governo. Isso reduziria seu padrão de lucratividade e a obrigaria a trabalhar com desagradáveis ciclos de médio e longo prazo. Atualmente, o ensaio acabou: as taxas de juros já retomaram a trajetória de alta e estão no caminho para atingir antigos recordes.

Por tudo isso, se tomarmos elementos trazidos pelo próprio autor, o "modelo de sociedade" do ciclo petista seria mais precisamente definido como social-liberal, o que alteraria o sentido histórico apresentado no ensaio.

Em suma, ao tentar coordenar a "cultura política” pemedebista com o conflito entre diferentes "modelos de sociedade", Nobre acaba enfraquecendo sua interpretação, uma vez que não apresenta parâmetros conceituais mínimos para que os termos do debate econômico sobre desenvolvimento ganhem coerência histórica e teórica. ${ }^{2}$

Por último, mas não menos importante: ao privilegiar uma terminologia genérica, o autor se esquivou de um nexo concreto entre o pemedebismo e os modelos de sociedade: o financiamento empresarial dos partidos políticos. Em outras palavras, quem compra o condomínio leva um lote maior, seja por meio do desmonte do nacional-desenvolvimentismo (a exemplo da venda da Vale do Rio Doce por FHC), seja por meio de sua reinvenção como farsa (das construtoras brasileiras em tempos de Copa do Mundo ou das bolhas especulativas de Eike Batista financiadas pelo BNDES). Ao abster-se de qualquer menção ao tema, seu esquema analítico se enfraquece mais uma vez.

\section{Conclusão}

Ao contrário do lulismo de André Singer, que ao fim e ao cabo legitima os limites do chamado "reformismo fraco" dos governos petistas por meio da hipótese do "conservadorismo popular", o pemedebismo é um conceito crítico, por dois motivos. Em primeiro lugar, porque identifica, em perspectiva histórica, os obstáculos autoritários que blindam o sistema político brasileiro contra as demandas sociais. Ao caracterizar os procedimentos típicos do condomínio pemedebista, miram-se alguns alvos importantes de uma reforma política que "democratizasse a democracia" no Brasil. Em segundo lugar, porque aponta para a necessidade de superação estrutural desses entraves, considerando que a única postura capaz de executar o desafio é o antipemedebismo. Justamente por isso, o ensaio está bem posicionado para compreender a natureza política das revoltas de junho de 2013, identificando os limites estruturais do sistema partidário brasileiro em geral, e do PT em particular, para qualquer superação ou ruptura da cultura política pemedebista.

O ensaio, contudo, não foi capaz de realizar o nexo entre "cultura política" e "modelo de sociedade". Primeiro, pela indeterminação com que emprega os termos desenvolvimento e desenvolvimentismo. Segundo, por não abordar com a devida importância o financiamento empresarial do sistema partidário como verdadeira base material do pemedebismo. De que maneira, por exemplo, as várias frações da classe dominante, escondidas por trás do condomínio, operam e se beneficiam com o "fim da polarização"? Afinal, não seria o capital que compra os partidos políticos a verdadeira torrente de água suja que movimenta o imobilismo? 
Notas

l É possível que essa imprecisão tenha origem na hipótese de Nobre sobre a obsolescência do paradigma da formação nacional, expressa no artigo "Depois da "formação" publicado na revista Piaui em novembro de 2012. Ao considerar que o problema da formação está historicamente suplantado desde a crise dos anos 1980, Nobre pretere as teorias do desenvolvimento, do subdesenvolvimento e da dependência como perspectivas não mais válidas para compreender e transformar o que chama de "nova realidade brasileira". Como alternativa, acredita na necessidade de "deixar para trás velhos fantasmas teóricos e práticos" e criar uma nova agenda, adequada à chamada "lógica das redes" e a um "novo padrão de modernização" do Brasil, caracterizado por uma "margem de manobra inédita" (Nobre, 2012 , p.77). Talvez por isso empregue os termos desenvolvimento e desenvolvimentismo de maneira indeterminada, já que caracterizá-los implicaria tomar uma posição clara dentro de um paradigma que ele mesmo considera obsoleto. Discutir os pressupostos teóricos desta imprecisão, contudo, está muito além do objetivo desta resenha.

2 Outra imprecisão foi cometida no território da sociologia: em seu debate com Singer anexado ao livro, Nobre afirma ter "muitas dúvidas em relação ao poder explicativo da noção de 'subproletariado"” (2013, p.175). Ele mesmo, contudo, emprega a estereotipada categoria de "povão" (2013, p.132) para identificar a base social lulista. Mas esse seria outro debate.

\section{Referências}

COSTA, E. A politica salarial no Brasil. 1964-1985: 21 anos de arrocho salarial e acumulação predatória. São Paulo: Boitempo, 1997.
NOBRE, M. Depois da "formação". Piaui, n.74, p.74-77, nov. 2012. . Imobilismo em movimento. São

Paulo: Companhia das Letras, 2013.

Joana Salém Vasconcelos é formada em História pela USP (2010) e é mestre em Desenvolvimento Econômico pelo Instituto de Economia da Unicamp (2013). É professora do curso de Licenciatura em Geografia das Faculdades Integradas de Ciências Humanas, Saúde e Educação de Guarulhos.@-joana.salem@gmail.com

I Faculdades Integradas de Ciências Humanas, Saúde e Educação de Guarulhos, Guarulhos/SP, Brasil. 